\title{
Short communication: Behavior of different Shiga toxin-producing Escherichia coli serotypes (O26:H11, 0103:H2, 0145:H28, 0157:H7) during the manufacture, ripening, and storage of a white mold cheese
}

\author{
S. D. Miszczycha, ${ }^{*}$ N. Bel,† P. Gay-Perret, † V. Michel,† M. C. Montel, $\ddagger$ and D. Sergentet-Thevenot ${ }^{*}{ }^{1}$ \\ ${ }^{*}$ Research Group on Bacterial Opportunistic Pathogens and Environment, Université de Lyon, VetAgro Sup, Campus Vétérinaire de Lyon, \\ UMR 5557 Ecologie Microbienne CNRS, 69622 Villeurbanne, France \\ †Actalia, 74800 La Roche-sur-Foron, France \\ fINRA, UR 545, Recherches Fromagères, 15000 Aurillac, France \\ §Laboratoire d'Étude des Microorganismes Alimentaires Pathogenes, French National Reference Laboratory for Escherichia coli including \\ Shiga Toxin-Producing E. coli, Université de Lyon, VetAgro Sup, Campus Vétérinaire de Lyon, 69280 Marcy l'Etoile, France
}

\begin{abstract}
Ruminants are healthy carriers of Shiga toxinproducing Escherichia coli (STEC). If good hygienic and agricultural practices at the farm level, especially during the milking process, are not adequately followed, milk and dairy products made with raw milk could become contaminated. Sporadic cases and rare food outbreaks have been linked with dairy products. Consequently, understanding STEC behavior in cheeses would help to evaluate risks for human health. The behavior of 4 different STEC strains belonging to the serotypes O26:H11, O103:H2, O145:H28, and O157:H7 were monitored during the manufacture, ripening, and storage of a white mold soft cheese. These strains, originating from dairy products, were inoculated individually in raw milk from cow at $10^{2} \mathrm{cfu} / \mathrm{mL}$. During the first 24 to $36 \mathrm{~h}$ of the manufacturing stage, the STEC level increased by 2 to $3 \log _{10} \mathrm{cfu} / \mathrm{g}$. Over the course of the ripening stage, the concentration of the non-O157 STEC remained relatively constant, whereas a decrease of the E. coli O157:H7 concentration was observed. During the storage stage, the level of the different nonO157 STEC strains decreased slowly in the core and in the rind of cheeses. The non-O157 STEC level reached between 3.1 and $4.1 \log _{10} \mathrm{cfu} / \mathrm{g}$ at $\mathrm{d} 56$. Interestingly, the concentration of the E. coli $\mathrm{O} 157: \mathrm{H} 7$ strain decreased dramatically: the strains remained detectable only after enrichment. During ripening and storage, STEC levels were generally higher in rinds than in cheese cores. In contrast to what was seen in cheese cores, the $E$. coli O157:H7 strain remained enumerable in rinds during these steps. These results highlight that STEC can grow during the manufacture and survive during the ripening and storage of a white mold soft cheese.
\end{abstract}

Received December 22, 2015

Accepted March 4, 2016.

${ }^{1}$ Corresponding author: delphine.sergentet@vetagro-sup.fr
Key words: white mold soft cheese, Shiga toxinproducing Escherichia coli, challenge tests, behavior

\section{Short Communication}

Shiga toxin-producing Escherichia coli (STEC) are food-borne pathogens that could be responsible, after ingestion, for a variety of clinical outcomes in humans ranging from diarrhea to hemorrhagic colitis, and in some severe cases can cause hemolytic-uremic syndrome and even death (Nataro and Kaper, 1998; Paton and Paton, 1998). Ruminants are healthy carriers of STEC; if good hygienic and agricultural practices at farm level, especially during the milking process, are not adequately followed, milk and dairy products made with raw milk could become contaminated (Little et al., 2008; Farrokh et al., 2013). Strains of STEC have been found in raw milk and raw milk cheeses and have been implicated in rare outbreaks (Espié et al., 2006; Baylis, 2009; Farrokh et al., 2013). Contamination by STEC is also an important microbiological cause of dairy product recalls in Europe (RASFF, 2014) and in France (http://agriculture.gouv.fr/rappel-de-fromagesde-chevre-contamines-par-ecoli).

Several studies have been dedicated to the investigation of STEC behavior during the manufacture and ripening of cheeses (Montet et al., 2009; Peng et al., 2013a; Farrokh et al., 2013). In a recent study (Miszczycha et al., 2013), we demonstrated that various STEC strains found in raw milk products and belonging to the prevalent serotypes O26:H11, O103:H2, O145:H28, and O157:H7 were able to survive during cheese manufacturing in different cheese technologies (blue-type cheeses, lactic cheeses, 2 uncooked pressed cheeses, and cooked pressed cheeses). Interestingly, when growth was observed during the first manufacturing step, STEC levels subsequently decreased progressively in cheeses that were ripened for more than 6 mo. Working specifically with white mold soft cheese, Montet et al. (2009) 
showed that different STEC strains are able to grow during the first hours of manufacture (by 1 to $2 \log _{10}$ $\mathrm{cfu} / \mathrm{g}$ ) before decreasing in the early stages of ripening. A caveat of their study was that STEC strains were not inoculated individually in the milk (rather, a mixture of 2 strains were inoculated simultaneously in the raw milk), and those assays were performed with mutant strains of STEC with plasmidic different antimicrobial resistance. In those conditions, it cannot be excluded that interactions between the different STEC strains had an effect on their behavior. The development of new isolation agar plates (Possé et al., 2008) has allowed the enumeration of the most prevalent STEC serotypes in dairy products such as E. coli O26:H11 or E. coli O103:H2 (DGAL, 2010). Thus, the aim of our study was to investigate the behavior of wild-type STEC strains belonging to the serotypes O26:H11, O103:H2, O145:H28, and O157:H7 during the manufacture, ripening, and storage of a white mold soft cheese.

Four different STEC strains were used: one E. coli O26:H11 (strain 7501A), one E. coli O103:H2 (strain F73120), one E. coli O145:H28 (strain F324), and one E. coli O157:H7 (strain 721.4). All were isolated from milk and milk products and carried virulence genes eae and either stx1 or stx2 (Miszczycha et al., 2013). The tested serotypes were chosen according to their pathogenicity and their prevalence in dairy products (DGAL, 2010; Farrokh et al., 2013). All strains were kept in cryo beads (AEB 400100, AES Laboratories, Combourg, France) and maintained at $-80^{\circ} \mathrm{C}$.

The inoculation protocol has been described in detail in a previous publication (Miszczycha et al., 2013). Briefly, each strain was revived in $10 \mathrm{~mL}$ of brain heart infusion (bioMérieux, Marcy l'Etoile, France) by incubation at $37^{\circ} \mathrm{C}$ for $24 \mathrm{~h}$. One hundred microliters was then transferred into $10 \mathrm{~mL}$ of buffered peptone water (bioMérieux), incubated at $37^{\circ} \mathrm{C}$ for $24 \mathrm{~h}$, and stored at $8^{\circ} \mathrm{C}$ for $48 \mathrm{~h}$ to simulate the storage conditions of milk and to cold-adapt the strains. After turbidity measurements (Densimat photometer, bioMérieux), the coldadapted strains were diluted to inoculate the raw milk before the maturation step at $10^{2} \mathrm{cfu} / \mathrm{mL}$. Inoculation levels were checked by plating inocula on plate count agar (bioMérieux). Colonies were enumerated after 24 $\mathrm{h}$ of incubation at $37^{\circ} \mathrm{C}$. All strains were inoculated separately into raw milk, in triplicate. For each trial, we checked that E. coli O26:H11, O103:H2, O145:H28, and $\mathrm{O} 157: \mathrm{H} 7$ were not initially present in the raw milk (Miszczycha et al., 2013).

Cheeses were made in an experimental cheese dairy facility at INRA, Unité de Recherches Fromagères, Aurillac, France. The white mold soft cheeses were prepared with raw cow milk. The cheesemaking protocol followed in our study was very similar to the one described by Montet et al. (2009); the only differences were that (1) whole milk was used instead of microfiltered milk, (2) mesophilic starter MM101 from Danisco (Sassenage, France) were used, (3) thermophilic starter type TAO52 (Streptococcus thermophilus) and 25 DCU/100 L (Danisco) were also added, (4) the inoculated milk was matured for 90 min at $36^{\circ} \mathrm{C}$ instead of for $2 \mathrm{~h}$ at $32^{\circ} \mathrm{C}$, and (4) that the cheeses were ripened over 14 instead of $20 \mathrm{~d}$. The cheeses were packaged at d 14 and stored at $4^{\circ} \mathrm{C}$ until d 28. They were then stored at $8^{\circ} \mathrm{C}$ until d 56 (Figure 1).

Samples used to enumerate STEC strains were taken from milk and cheese cores at different stages of cheesemaking (the zero sampling started when the STEC have been inoculated in the raw milk, maturation, cutting, molding, molding $+4 \mathrm{~h}$, removing the molds, brining), and in cheese cores and rinds during ripening (d 1.5, 7, and 14) and storage (d 28, 42, and 56). Both $\mathrm{pH}$ and water activity were recorded as previously described (Miszczycha et al., 2013).

The counting and detection procedure of STEC strains were the same as previously described (Miszczycha et al., 2013). Briefly, aseptically taken samples of $50 \mathrm{~mL}$ of milk or $50 \mathrm{~g}$ of cheese were diluted (1:5) in sterile buffered peptone water and homogenized for $60 \mathrm{~s}$ in a stomacher (AES Laboratories). Further decimal dilutions were performed with sterile tryptone salt (bioMérieux) and $100 \mu \mathrm{L}$ were spread onto selective agars in triplicate. For the enumeration of serogroup 0157, each sample was plated onto O157:H7 ID medium (bioMérieux) supplemented with $0.05 \mathrm{mg} / \mathrm{L}$ of cefixime and $2.5 \mathrm{mg} / \mathrm{L}$ of tellurite. For the enumeration of serogroups O26, O103, and O145, each sample was plated onto a specific medium as described by Possé et al. (2008). All enumerations were performed in triplicate. After incubation for $24 \mathrm{~h}$ at $37^{\circ} \mathrm{C}$, presumptive bacteria were tested by real-time PCR. When a strain could not be enumerated in a sample, an enrichment step was performed [incubation of the remaining enrichment broth complemented with acriflavin $24 \mathrm{~h}$ at $41.5^{\circ} \mathrm{C}$ (Savoye et al., 2011) for the STEC O26 and O157 and at $37^{\circ} \mathrm{C}$ for the STEC O103 and O145 (ISO, 2012)], and STEC strain detection was performed by immunomagnetic separation with Dynabeads (Invitrogen, Cergy Pontoise, France) to check whether the target strain was still present (Miszczycha et al., 2013).

The identification and characterization of the target bacteria were performed by real-time PCR as previously described (Nielsen and Andersen, 2003; Perelle et al., 2004, 2005; Madic et al., 2010; Miszczycha et al., 2012). The serotype effect was tested. A negative binomial generalized linear model (GLM) was used in R ( $R$ Development Core Team, 2005). A probability level of $P<0.05$ was taken to indicate statistical significance. 


Raw milk
Starter cultures / STEC inoculation

Milk maturation

$90 \mathrm{~min}$ at $36^{\circ} \mathrm{C}$

Renneting (35 $\mathrm{mL}$ of rennet/100 L)

$40 \mathrm{~min}$ at $36^{\circ} \mathrm{C}$

\section{Cutting}

Pieces of $2 \mathrm{~cm}^{3}$

\section{Moulding}

\section{Acidification / draining turning}

$20 \mathrm{~h}$ at $20^{\circ} \mathrm{C}$ with 3 turnings

$20^{\circ} \mathrm{C} \quad$ Removing the molds

$25 \mathrm{~min}$ at $10^{\circ} \mathrm{C} \quad$ Brining

$4 \mathrm{~h}$ at $13^{\circ} \mathrm{C} \quad$ Drying

$14 \mathrm{~d}$ at $13^{\circ} \mathrm{C} \quad$ Ripening

$14 \mathrm{~d}$ at $4^{\circ} \mathrm{C}$,

\section{Packaging and storage}

then $28 \mathrm{~d}$ at $8^{\circ} \mathrm{C}$

\footnotetext{
Figure 1. Flow diagram of the characteristics of the white mold soft cheese tested.
}

The concentration of all 4 STEC strains increased during the first 24 to $36 \mathrm{~h}$ of manufacturing (Figure 2 ). At the end of the manufacturing step, before ripening (d 1.5), the level of the STEC O103:H2 strain reached $5.68 \log _{10} \mathrm{cfu} / \mathrm{g}$. The STEC O26:H11 and
STEC O145:H8 strains increased to reach, respectively, 4.6 and $4.97 \log _{10} \mathrm{cfu} / \mathrm{g}$, whereas the level of the STEC O157:H7 strain reached $3.89 \log _{10} \mathrm{cfu} / \mathrm{g}$. During the first hours of cheesemaking, increases in counts were due to cell concentration within curd formation, which 
generally increases STEC concentration by a factor of approximately 10. Measured STEC abundances during these assays clearly indicate bacteria growth, as previously noted in both blue cheeses and uncooked pressed cheeses (Miszczycha et al., 2013). The growth of the STEC strain belonging to the serotype O157:H7 was lower than observed for the other serotypes tested. However, the growth of the STEC O157:H7 strain tested in our study was similar to what was observed with the same serotype during the manufacture of other cheeses (Govaris et al., 2002; D'Amico et al. 2010; Farrokh et al., 2013). During the initial stages, conditions for STEC growth were met as temperatures were consistently above $30^{\circ} \mathrm{C}$ and acidity levels remained sufficiently high (Glass et al., 1992). Twenty hours after the beginning of the manufacturing, when the cheeses were removed from the mold (fat $=22.7 \mathrm{~g} / 100 \mathrm{~g}$, fat in $\mathrm{DM}=48 \%$, moisture content in the fat-free cheese $=68.2 \%$, moisture/nonfat solid $=2.15, \mathrm{NaCl}=1.42$ $\mathrm{g} / 100 \mathrm{~g}$ ), pH remained above 5. Montet et al. (2009) also observed an increased STEC concentration during the manufacture of white mold soft cheeses. Although Montet et al. (2009) inoculated milk with initial STEC concentrations 10 times higher $\left(10^{3} \mathrm{cfu} / \mathrm{mL}\right)$ than the ones used in the present study, the maximum concentrations reached during the course of both experiments were similar (ranging between 5 and $6 \log _{10} \mathrm{cfu} / \mathrm{g}$ ). The mutant strains of STEC used by Montet et al. (2009) might have more difficulty growing than the strain originating from dairy products tested in the current work (furthermore, selective agar plates used in the 2 studies were not the same). Nutrient competition with the microflora already present in the raw milk and with the starter cultures added may also explain why STEC concentrations cannot reach more than $6 \log _{10} \mathrm{cfu} / \mathrm{g}$ in this type of cheese.

During ripening, in the core of the cheese, the $\mathrm{pH}$ gradually increased to reach 5.7 or 6.1 and the water activity remained constant around 0.98 until d 56 . The concentration of the STEC O26:H11 strain remained relatively constant, whereas the concentration of the STEC strains belonging to the serotypes O103:H2 and O145:H28 decreased slowly (less than $1 \log _{10} \mathrm{cfu} / \mathrm{g}$ ). The decrease of the STEC O157:H7 counts during ripening was higher than that of the other STEC serotypes, around $1.3 \log _{10} \mathrm{cfu} / \mathrm{g}$. During the storage period of the cheeses, the level of the different non-O157 STEC strains decreased slowly in cheese cores. By d 56 , concentrations reached $3.1 \log _{10} \mathrm{cfu} / \mathrm{g}$ for the STEC O26:H11 strain, $4.1 \log _{10} \mathrm{cfu} / \mathrm{g}$ for the STEC O103:H2 strain, and $3.4 \log _{10} \mathrm{cfu} / \mathrm{g}$ for the STEC O145:H28 strain. At the beginning of the storage step, the concentration of the STEC O157:H7 strain decreased dramatically, and the strains remained detectable only after enrichment. During ripening and storage, the level of the STEC O26:H11 strain was similar to that of STEC O103:H2 at $\mathrm{d} 14(P=0.971), 28(P=0.677)$, and $40(P$ $=0.971)$, and similar to that of STEC O145:H28 $(P>$ 0.07 for all days) except for d $56(P<0.05)$. The level of the STEC O103:H2 strain was higher than that of STEC O145:H28 strain from d 1 to $56(P<0.05)$. As noted previously (Miszczycha et al., 2013), the level of the STEC O157:H7 strain remained lower than that of the non-O157 strain $(P<0.05$ from d 1 to 56$)$.

During ripening, in the rind of the cheese the $\mathrm{pH}$ increased from 5 to 6.1 at d 14 and the water activity remained constant between 0.98 and 0.97 . The behavior of the STEC in cheese rinds remained relatively similar to the one in cheese cores with a slow decrease during the storage step (water activity slowly decreased during this step but remained above 0.96 whereas $\mathrm{pH}$ increased to reach 6.5 at d 56). For each strain, the level of STEC was generally higher in rinds than in cores, as observed previously (Peng et al., 2013b); higher pH values can explain this observation. Significant differences between cores and rinds were observed during the entire ripening and storage steps $(P<0.05)$ for the STEC strains belonging to the serotypes $\mathrm{O} 103: \mathrm{H} 2$ and O157:H7, but only at the end of the storage step for the STEC strains belonging to the serotypes O26:H11 and O145:H28. Interestingly, the STEC O157:H7 strain remained enumerable in cheese rinds during the ripening and the storage of the cheeses. Its level decreased to reach $1.3 \log _{10} \mathrm{cfu} / \mathrm{g}$ at $\mathrm{d} 56$.

These results are in line with previous observations, such as Montet et al. (2009), who observed a decrease of the STEC counts during white mold soft cheese ripening. However, the decreases of STEC counts (except for E. coli $\mathrm{O} 157: \mathrm{H} 7)$ observed in our study were lower than those previously observed by those authors. The co-inoculation of 2 different STEC strains may have caused a competition phenomenon between STEC strains, which could explain the important decrease of STEC counts during ripening observed by Montet et al. (2009). Other authors have also reported an important decrease of the rate of STEC O157:H7 strains during the ripening and the storage of different cheeses (Vernozy-Rozand et al., 2005; D'Amico et al., 2010), but these strains remained generally detectable after enrichment.

In conclusion, we demonstrated that STEC belonging to the serotypes O26:H11, O103:H2, O145:H28, and O157:H7 in artificially contaminated milk can grow during the manufacture of a white mold soft cheese and can survive during the ripening and the storage of this cheese. These results underline the importance of preventing the presence of the STEC by measures such as good hygiene practices at farm level and during 
processing (limiting fecal contamination of the teats), implementation of prophylactic actions in livestock (detection and isolation of high shedders of STEC, use of probiotics, antimicrobials, or altering diet), and detection of STEC early in the milk and in the initial phases of cheese manufacturing and long before cheeses reach the food retail stage (improvement of tool detection and sampling strategy). As already noted (Miszczycha et al., 2013), the STEC strain belonging to the sero- type O157:H7 appears to have more difficulty to grow and survive in the cheese. In our study, STEC were inoculated at a high concentration, higher than those found in naturally contaminated milk. An interesting new development would be the monitoring of growth and survival of STEC in white mold soft cheeses using lower, more realistic concentrations or naturally contaminated milks. It would also be interesting to test other STEC strains belonging to the serotypes

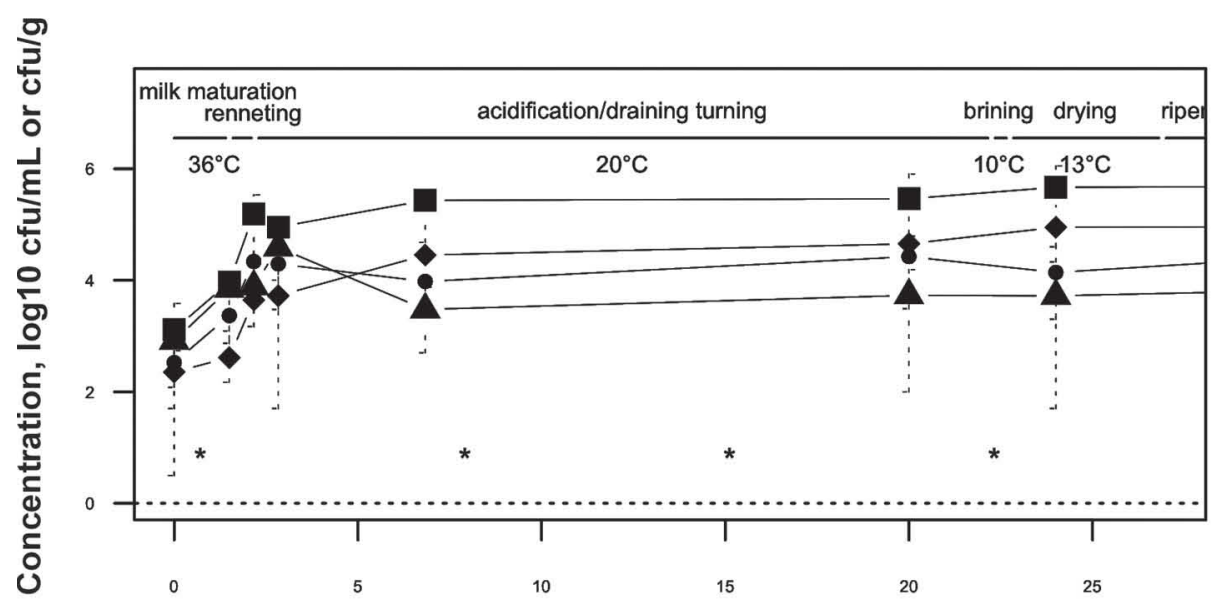

- serotype O26:H11 in core

o serotype O26:H11 in rind

A serotype 0157:H7 in core

$\Delta$ serotype 0157:H7 in rind

- serotype O103:H2 in core

口 serotype 0103:H2 in rind

- serotype 0145:H28 in core

$\diamond$ serotype 0145:H28 in rind

Time (manufacture), $\mathbf{h}$

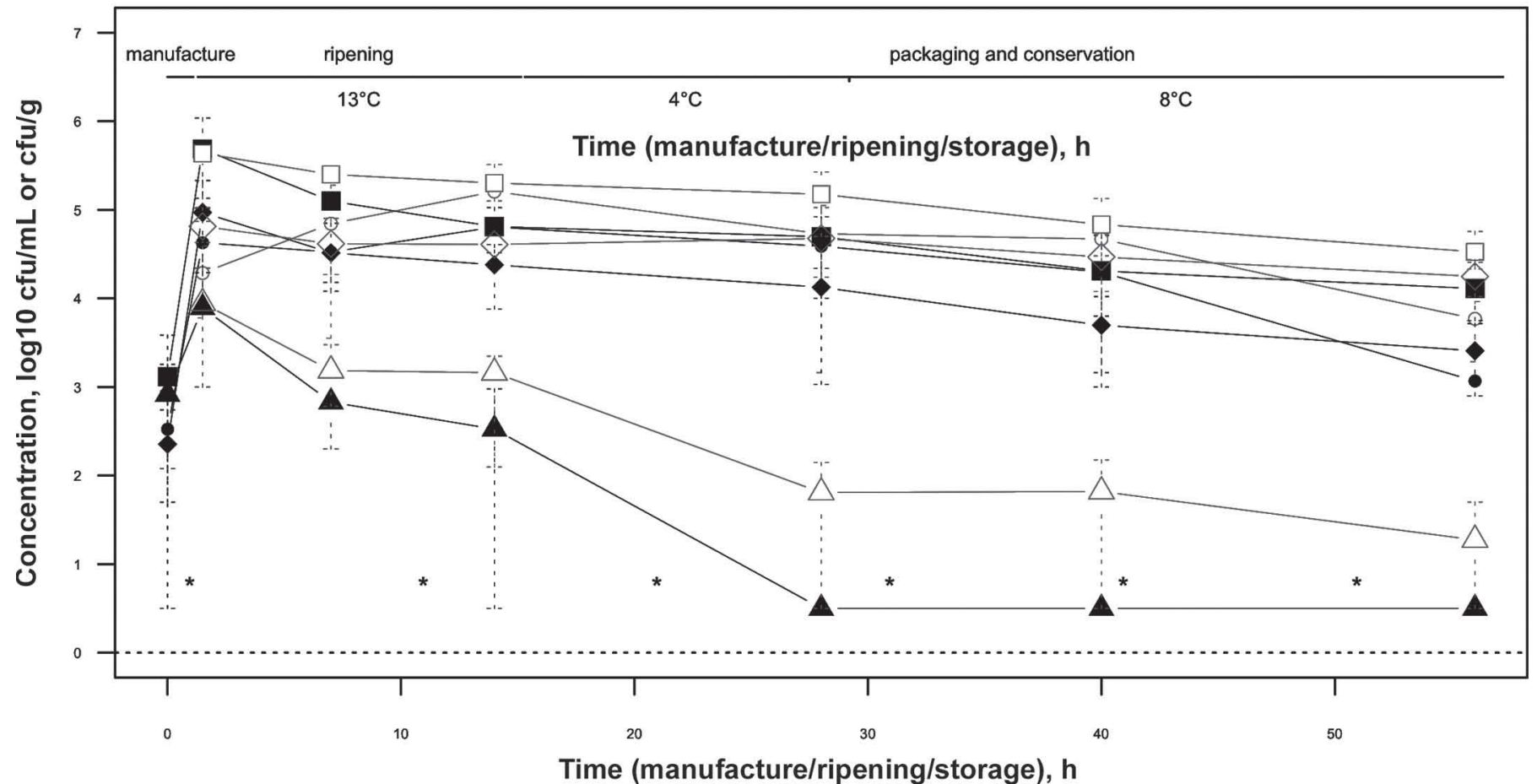

Figure 2. Average counts of Shiga toxin-producing Escherichia coli (STEC) belonging to the different serotypes during the manufacture of the white mold soft cheese. Vertical bars represent minimal and maximal enumeration values; an asterisk $\left(^{*}\right)$ represents counts below the enumeration limit, detectable after enrichment. 
frequently isolated in dairy products and to determine the molecular mechanisms involved in their growth and survival and to explain their different behavior.

\section{ACKNOWLEDGMENTS}

The authors sincerely thank René Lavigne from the UR 545 Recherches Fromagère (INRA, Aurillac, France) for his participation in cheesemaking, Sarah Ganet and Paul Madeddu from VetAgro-Sup for their technical assistance, and Kirsty Burnet and Rémi Vergnon from University of Sheffield (Sheffield, United Kingdom) for their assistance in the statistical analysis and the English proofreading of the manuscript. This work was funded by the CNIEL (Centre National Interprofessionnel de l'Economie Laitière, Paris, France) through a financial support.

\section{REFERENCES}

Baylis, C. L. 2009. Raw milk and raw milk cheeses as vehicles for infection by verocytotoxin-producing Escherichia coli. Int. J. Dairy Technol. 62:293-307.

D'Amico, D. J., M. J. Druart, and C. W. Donnelly. 2010. Behavior of Escherichia coli O157:H7 during the manufacture and aging of Gouda and stirred-curd Cheddar cheeses manufactured from raw milk. J. Food Prot. 73:2217-2224.

DGAL. 2010. Bilan 2009 des plans de surveillance et de controle mis en oeuvre par la DGAL - Plan de surveillance de la contamination par Escherichia coli STEC (VTEC) des viandes hachées et des fromages au lait cru pour l'année 2009. Pages 51-53 in Ministère de l'Agriculture, de l'Alimentation, de la Pêche, de la Ruralité et de l'Aménagement du Territoire, France. Direction Générale de l'Alimentation, Paris, France.

Espié, E., P. Mariani-Kurkdjian, F. Grimont, N. Pihier, V. Vaillant, S. Francart, I. Capek, and H. De Valk. 2006. Shiga-toxin producing Escherichia coli O26 infection and unpasteurized cows cheese, France, 2005. In Abstract of the 6th International Symposium on Shigatoxin (verocytotoxin)-Producing Escherichia coli Infections. J. Sofronidis, ed. Melbourne, Australia. Cambridge Publ., West Leederville, Australia. Accessed Dec. 19, 2015. http://opac.invs. sante.fr/index.php?lvl=notice_display\&id=9418.

Farrokh, C., K. Jordan, F. Auvray, K. Glass, H. Oppegaard, S. Raynaud, D. Thevenot, R. Condron, K. De Reu, A. Govaris, K. Heggum, M. Heyndrickx, J. Hummerjohann, D. Lindsay, S. Miszczycha, S. Moussiegt, K. Verstraete, and O. Cerf. 2013. Review of Shiga-toxin-producing Escherichia coli (STEC) and their significance in dairy production. Int. J. Food Microbiol. 162:190-212.

Glass, K. A., J. M. Loeffelholz, J. P. Ford, and M. P. Doyle. 1992. Fate of Escherichia coli O157:H7 as affected by $\mathrm{pH}$ or sodium chloride and in fermented, dry sausage. Appl. Environ. Microbiol. $58: 2513-2516$.

Govaris, A., D. K. Papageorgiou, and K. Papatheodorou. 2002. Behavior of Escherichia coli O157:H7 during the manufacture and ripening of feta and telemes cheeses. J. Food Prot. 65:609-615.

ISO. 2012. ISO/TS 13136:2012. Microbiology of food and animal feed-Real-time polymerase chain reaction (PCR)-based method for the detection of food-borne pathogens - Horizontal method for the detection of Shiga toxin-producing Escherichia coli (STEC) and the determination of O157, O111, O26, O103 and O145 serogroups. Accessed Dec. 19, 2015. http://www.iso.org/iso/ catalogue_detail.htm?csnumber $=53328$.

Little, C. L., J. R. Rhoades, S. K. Sagoo, J. Harris, M. Greenwood, V. Mithani, K. Grant, and J. McLauchlin. 2008. Microbiological quality of retail cheeses made from raw, thermized or pasteurized milk in the UK. Food Microbiol. 25:304-312.

Madic, J., C. Peytavin de Garam, N. Vingadassalon, E. Oswald, P. Fach, E. Jamet, and F. Auvray. 2010. Simplex and multiplex realtime PCR assays for the detection of flagellar (H-antigen) $\mathrm{fliC}$ alleles and intimin (eae) variants associated with enterohaemorrhagic Escherichia coli (EHEC) serotypes O26:H11, O103:H2, O111:H8, O145:H28 and O157:H7. J. Appl. Microbiol. 109:1696-1705.

Miszczycha, S. D., S. Ganet, L. Dunière, C. Rozand, E. Loukiadis, and D. Thevenot-Sergentet. 2012. Novel real time PCR method to detect Escherichia coli O157:H7 in raw milk cheese and raw ground meat. J. Food Prot. 75:1373-1381.

Miszczycha, S. D., F. Perrin, S. Ganet, E. Jamet, F. Tenenhaus-Aziza, M. C. Montel, and D. Thevenot-Sergentet. 2013. Behavior of different Shiga-toxin producing Escherichia coli (STEC) serotypes in various experimentally contaminated raw milk cheeses. Appl. Environ. Microbiol. 79:150-158.

Montet, M. P., E. Jamet, S. Ganet, M. Dizin, S. Miszczycha, L. Duniere, D. Thevenot, and C. Vernozy-Rozand. 2009. Growth and survival of acid-resistant and non-acid-resistant Shiga-toxin-producing Escherichia coli strains during the manufacture and ripening of Camembert cheese. Int. J. Microbiol. 2009:653481.

Nataro, J. P., and J. B. Kaper. 1998. Diarrheagenic Escherichia coli. Clin. Microbiol. Rev. 11:142-201.

Nielsen, E. M., and M. T. Andersen. 2003. Detection and characterization of verocytotoxin-producing Escherichia coli by automated $5^{\prime}$ nuclease PCR assay. J. Clin. Microbiol. 41:2884-2893.

Paton, J. C., and A. W. Paton. 1998. Pathogenesis and diagnosis of Shiga toxin-producing Escherichia coli infections. Clin. Microbiol. Rev. 11:450-479.

Peng, S., W. Hoffmann, W. Bockelmann, J. Hummerjohann, R. Stephan, and P. Hammer. 2013a. Fate of Shiga toxin-producing and generic Escherichia coli during production and ripening of semihard raw milk cheese. J. Dairy Sci. 96:815-823.

Peng, S., K. Schafroth, E. Jakob, R. Stephan, and J. Hummerjohann. 2013b. Behaviour of Escherichia coli strains during semi-hard and hard raw milk cheese production. Int. Dairy J. 31:117-120.

Perelle, S., F. Dilasser, J. Grout, and P. Fach. 2004. Detection by 5'-nuclease PCR of Shiga-toxin producing Escherichia coli O26, O55, O91, O103, O111, O113, O145 and O157:H7, associated with the world's most frequent clinical cases. Mol. Cell. Probes 18:185-192.

Perelle, S., F. Dilasser, J. Grout, and P. Fach. 2005. Detection of Escherichia coli serogroup O103 by real-time polymerase chain reaction. J. Appl. Microbiol. 98:1162-1168.

Possé, B., L. De Zutter, M. Heyndrickx, and L. Herman. 2008. Novel differential and confirmation plating media for Shiga toxin-producing Escherichia coli serotypes O26, O103, O111, O145 and sorbitolpositive and -negative O157. FEMS Microbiol. Lett. 282:124-131.

R Development Core Team. 2005. R: A language and environment for statistical computing. R Foundation for Statistical Computing, Vienna, Austria. Accessed Dec. 19, 2105. http://www.R-project.org.

RASFF. 2014. RASFF for safer food-The Rapid Alert System for Food and Feed-2014 annual report. Accessed Dec. 19, 2015. http://ec.europa.eu/food/safety/rasff/index_en.htm.

Savoye, F., C. Rozand, M. Bouvier, A. Gleizal, and D. Thevenot. 2011. Optimized enrichment for the detection of Escherichia coli O26 in French raw milk cheeses. Lett. Appl. Microbiol. 52:603-609.

Vernozy-Rozand, C., C. Mazuy-Cruchaudet, M.-P. Bavai, V. Montet, A. Bonin, Dernburg, and Y. Richard. 2005. Growth and survival of Escherichia coli O157:H7 during the manufacture and ripening of raw goat milk lactic cheeses. Int. J. Food Microbiol. 105:83-88. 